\title{
Improving Classroom
}

Communication: The Effects of Virtual Social Training on Communication and Assertion Skills in Middle School Students

\section{OPEN ACCESS}

Edited by:

Miloš Kankaraš,

Organization for Economic CoOperation and Development, France

Reviewed by:

Raquel Artuch Garde, Public University of Navarre, Spain Agnese Capodieci,

University of Padua, Italy

*Correspondence:

Maria Teresa Johnson Maria.johnson@utdallas.edu

Specialty section:

This article was submitted to Educational Psychology,

a section of the journal

Frontiers in Education

Received: 10 March 2021 Accepted: 29 April 2021

Published: 13 May 2021

Citation:

Johnson MT, Troy AH, Tate KM, Allen TT, Tate AM and Chapman SB

(2021) Improving Classroom Communication: The Effects of Virtual Social Training on Communication and Assertion Skills in Middle

School Students.

Front. Educ. 6:678640.

doi: 10.3389/feduc.2021.678640
Maria Teresa Johnson ${ }^{1 *}$, Aimee Herron Troy ${ }^{1}$, Kathleen Michelle Tate ${ }^{1}$, Tandra Toon Allen ${ }^{1}$, Aaron Michael Tate ${ }^{2}$ and Sandra Bond Chapman ${ }^{1}$

${ }^{1}$ Social Cognition Lab, School of Behavioral and Brain Sciences, Center for BrainHealth, University of Texas at Dallas, Dallas, TX, United States, ${ }^{2}$ Emerging Technology Lab, School of Behavioral and Brain Sciences, Center for BrainHealth, University of Texas at Dallas, Dallas, TX, United States

This study examined the relationship between teacher identification of socially at-risk adolescents and baseline student social competency levels. Additionally, the feasibility and effects of an eight-session, virtual social training were analyzed. Upon completion of the virtual social training, the transfer effects from the targeted intervention into the general education classroom were determined. Study participants $(\mathrm{N}=90)$ were comprised of sixth, seventh and eighth-grade students from four public middle schools in Dallas, Texas. Data was collected through classroom teacher questionnaires to measure students' baseline social behaviors. In addition, pre-post student performance measures in the areas of affect recognition, social inference, and social attribution were administered. Results revealed that middle school teachers were effective identifiers of students with lagging social skills. Baseline ratings of social skills showed a high positive association between student affect recognition and teacher rating of participant total social skills including communication, cooperation, responsibility, and self-control. A high negative association was found between student affect recognition and problem behaviors. A high negative association was also found between student perspective-taking and hyperactivity and externalizing behaviors. Student pre-post test performance measures revealed significant improvement in affect recognition, attribution, and social inferencing after undergoing the virtual social training. At the time of a $5^{\circ}$ week follow up, teachers rated participants' social skills in the areas of communication and assertion as significantly improved. Sixty-eight percent of participants reported increased confidence in social communication skills such as relating, maintaining, adapting, and asserting thoughts after the training. Preliminary findings from this small-scale study provide evidence that a brief eight-session, virtual social training in middle school is a feasible delivery model that can achieve positive effects on social behavior, and that teacher referral was a reliable way to identify students who could benefit from the training. Incorporating teacher perspective aided in translating a previously labbased training into an ecologically relevant setting while addressing a programming need to meet the social demands of adolescence.

Keywords: social skills, middle school, adolescence, teachers, virtual social training, at-risk 


\section{INTRODUCTION}

Middle school, commonly grades six through eight in US education, is an opportune environment for teachers to observe and measure social behavior change. Early adolescence is recognized as a maturational period of learning and development, with heightened receptivity to specific social contexts (Giovanelli et al., 2020). With high demands for communication, cooperation, and assertion, a middle school classroom is rich with social interaction, potentially leading to problem behaviors. In fact, during middle school, students may face considerable challenges ranging from peer pressure, academic competition, and social comparison among peers, which may result in decreased connectedness with teachers, school staff, and classmates (Cappella et al., 2019). Furthermore, how middle schoolers respond to peer-evaluative stress may, in part, influence tendencies to withdraw from social interactions (Kaeppler and Erath, 2017). Given this critical role of peer interaction during adolescence, greater incorporation of efforts to boost positive communication methods and resiliency in the face of negative peer contagion may prove beneficial (Rapee et al., 2019). Educational practices focused predominantly on rudimentary social skill behaviors such as eye contact, greetings, turn-taking, and friendship-building may fall short in building socially confident and capable communicators. The tendency in traditional public education beyond elementary school has been to assume that children will automatically acquire nuanced social skills as part of the developmental process (Ogilvy, 1994). However, since the adolescent brain is still developing, it needs to be molded and shaped to learn and adapt during this window of neural reorganization (Blakemore et al., 2010).

As early adolescents develop, between 11 and $14^{\circ}$ years of age, the social rules and demands become more abstract and require higher levels of social information processing. According to the Crick and Dodge (1994) model of social information processing (SIP), individuals in social situations: 1) perceive and encode the situational and social cues, 2) form a mental representation and interpretation of the situation, 3) select a goal or desired outcome for the interaction, 4) recall or construct possible reactions to the situation, 5) evaluate these reactions, and, finally, 6) initiate what they expect to be an adequate action. Additionally, developing complexities of social competency in adolescence include an awareness of another person's needs, a gradual increase in perspective-taking skills, and an ability to decode others' emotional cues to understand intentions (Ma et al., 2020).

Of particular interest in recent research is the social performance and behavior of adolescents that attend middle schools predominately with low social-economic status who may be at risk for delayed or stalled social reasoning skills. With 155,000 students and 239 schools, the Dallas Independent School District (DISD) is one of the nation's largest districts with $92 \%$ of its students Black or Latino and overwhelmingly low-income (Gándara and Orfield, 2021). Previous research within DISD has found that investing time in cognitive training during regular school hours with at-risk middle school students, could serve to enhance the development of higher-order thinking, thereby promoting the developmental trajectory of cognitive skills (Gamino et al., 2014). As such, utilizing a socially based cognitive training for students who lack social engagement or have difficulty with social perception and reasoning, could mediate a variety of cognitive breakdowns, both internally in terms of confidence and comfort level, and externally in regards to school-specific relationships and social communication. If left unaddressed, these breakdowns are likely to persist in at-risk populations during the development of the social self.

A systematic review on Social-Emotional Learning (SEL) programs conducted by the Collaborative for Academic, Social, and Emotional Learning (CASEL) among others found that SEL programs yield many benefits for children and adolescents, however, as of 2018, only 11 out of 50 states had freestanding K-12 SEL standards (Payton et al., 2008; Eklund et al., 2018). In a summary of randomized, controlled trials heavily focused on social-cognitive theory, it was suggested that youth are most likely to benefit when receiving individual-level behavioral skills, family level support and communication, and autonomous motivational support from the broader social environment, which could include the school system and educators (Wilson et al., 2017). Likewise, an additional meta-analysis revealed continued longterm benefits following program participation when investigating the longer-term impact of exposure to SEL programming in the school (Taylor et al., 2017). Finally, Mahoney and colleagues examined four large-scale meta-analyses on student outcomes related to participating in school-based SEL programs and found that although SEL programs can result in positive student outcomes socially and academically, it is prudent that multiple stakeholders (policymakers, funders, educators, researchers, and families) work together to ensure that as many students as possible benefit from well-conceptualized and wellimplemented SEL programs (Mahoney et al., 2018).

Two large-scale studies of more than 25,000 students across elementary, middle, and high school found that students in lower grades reported greater cognitive-behavioral and emotional engagement than those in middle and high school (Wang and Eccles, 2012; Yang et al., 2018). Additionally, when examining recent trends in student social-emotional learning, it was found that self-efficacy, social awareness, and, to a lesser degree, selfmanagement decrease after Grade 6 (West et al., 2020). Furthermore, teachers are recognized within the school setting as first identifiers and responders to the social needs of students, yet several studies point to a lack of help from school policies or clear lines of support once educators have observed social difficulties (Solberg, et al., 2020; Nyborg, et al., 2020). As such a process to accurately identify and then refer for social support in middle school may be lacking. A group of researchers conducted an analysis of available social skills assessments to assist middle school teachers in the accurate identification of students struggling socially and found that only 10 out of 73 potential tools were identified as a strong assessment choice (Haggerty et al., 2011). One measure identified as appropriate was the Social Skills Improvement System, as it includes direct teacher observation ratings of social behavior such as assertion, communication, responsibility, and self-control as well as a 
problem behavior scale for internalizing and externalizing behaviors, among others (Gresham and Elliot, 2008).

The window of dynamic growth and autonomy in adolescence may offer insight into the importance of intersections between developmental social neuroscience, social-emotional learning, and technology (Giovanelli et al., 2020). Evidence suggests that how technology users interact in a virtual world is strongly associated with their behavior and personality in the real world (Bayraktar and Amca, 2012; Wohn and Wash, 2013). In a paper outlining foundational principles required to ensure learner immersion, the presence and representation of self in a virtual world was found to be critical in promoting deep levels of social engagement (Mount et al., 2009). Additional studies have supported utilizing an avatar-driven, virtual learning platform as a social training tool for children and young adults with high functioning autism spectrum disorder, specifically for socialcognitive skills such as theory of mind and affect recognition (Wainer and Ingersoll, 2011; Kandalaft et al., 2013; Maskey et al., 2014; Didehbani et al., 2016; Zhao et al., 2020). Results offered promising data to support the use of three-dimensional virtual platforms as a social training tool but may have been limited in terms of generalization, as the studies were conducted in a controlled laboratory setting as opposed to the natural context of middle school. Although modern technology can provide a robust platform to engage and motivate learners, it is also necessary to balance state-of-the-art solutions with human interaction, mentorship and strong teacher-student relationships (Kamińska et al., 2019). Implementation of a social skill training utilizing technology at the middle school level may result in an increase in student engagement and attention when the curricular content matches students' developmental interests or is delivered in a novel way, unique to student age and learning style. Moreover, when SEL programs honor an individual's desire to achieve social competencies and respect the interests, trends, and needs of adolescents, motivation can be captured along with instilling the beginnings of a mindset shift (Yeager, 2017).

Given the importance of identifying and supporting adolescents struggling socially in middle school, the purpose of this study was to 1) examine the relationship between teachers' ratings of student social skills and student baseline performance on standardized measures of social competency, 2) analyze the feasibility and preliminary effects of implementing an eightsession virtual social training with strategy-based coaching for identified adolescents in the public school setting, and 3) determine transfer effects from the targeted social skill training to the general education classroom, as reported by teacher observations $5^{\circ}$ weeks following the training.

We hypothesized that 1 ) teachers are reliable identifiers of middle school students with lagging social skills; 2) the implementation of an eight-session virtual social training would be feasible within a naturalized context of public school, as evidenced by student participant improvements in measures of emotion recognition and social attribution; and 3) improvement on other related social communication skills observed by teachers in the classroom setting.

\section{MATERIALS AND METHODS}

\section{Participants}

Study participants were sixth, seventh, and eighth-grade students throughout four public middle schools in Dallas, Texas. Procedures were approved by the Institutional Review Board at the University of Texas at Dallas and the Dallas Independent School District Research Review Board. All middle school teachers who identified potential students for the study were given the opportunity to provide written informed consent upon student enrollment and take part in completing teacher rating scales. Cumulatively, 116 students were identified for potential participation across the four middle schools. Of this pool, 26 students did not enroll in the study due to frequent suspension, academic probation, transient attendance, and/or lack of parental consent, leaving 90 students and their parents or legal guardians who signed informed assent (student) and consent (parent or guardian). Of the 90 student participants, 40 were in the sixth grade, 27 were in seventh grade, and 23 were in eighth grade. The average age of the students was $12.4^{\circ}$ years (range $11-14^{\circ}$ years) and included $8 \%$ Caucasian, 73\% Hispanic, 13.5\% AfricanAmerican, and 5.5\% Asian or Other race. Sixty-one males and 29 females comprised the total student sample.

\section{Procedure}

All procedures were conducted at four Dallas public middle schools and the Center for BrainHealth ${ }^{\circledR}$ at the University of Texas at Dallas. Study staff was comprised of three master level clinicians and two graduate research assistants. An informational flier introducing the study was made available to all teachers at each school. Additionally, teachers were provided examples of social themes that would be covered in the virtual social training, such as initiating and maintaining conversations, understanding the quality of relationships and interactions, and recognizing and responding to peer pressure and adult authority. Teachers were asked to nominate individuals for participation in the program via a brief student identification form. Teachers reported the following description(s) of each student's social behavior in the classroom as the reason for referral: isolated or withdrawn, awkward conversational exchanges, limited group participation, rigid thinking, and/or skewed perceptions or reactions. Teachers could indicate more than one reason for referral. The most frequently reported reasons for referral were shy and withdrawn social behavior and awkward conversational exchanges (Table 1). For this study, adolescents between the ages of 11-14, who spoke fluent English, as defined by being able to use five-to-six word phrases and follow one-to-two step verbal directions, were eligible to participate. A letter and flyer were then sent home to the teacher-identified students to inform the parents of the availability of the study. All parent forms were proffered in English and Spanish. Interested parents were asked to contact study staff to complete informed consent procedures and provide general student demographics such as ethnicity, language spoken at home, medical history including prescribed medications and/or treatments, pre-existing psychiatric/mental illness, educational diagnosis (such as non-clinical, attention 
TABLE 1 | Reason for Teacher Referral. Teachers marked which reason(s) applied for the students they reported $(N=90)$.

\begin{tabular}{lcc} 
Referral reason & $\begin{array}{c}\text { Number of } \\
\text { referrals }\end{array}$ & $\begin{array}{c}\text { Percentage of total } \\
\text { sample (\# of } \\
\text { referrals/N) }\end{array}$ \\
\hline Isolated or withdrawn & 38 & $42 \%$ \\
Awkward conversational & 43 & $48 \%$ \\
exchanges & 25 & $28 \%$ \\
Limited group participation & 15 & $15 \%$ \\
Rigid thinking & 30 & $33 \%$ \\
Skewed perceptions or reactions & & \\
\hline
\end{tabular}

deficit hyperactivity disorder, other health impairment, autism spectrum disorder, and learning disability), and a brief description of their child's social skills. Study staff coordinated with teachers to determine which class period during the school day participants could complete the virtual social training and related assessments. Students also provided input toward which class periods were preferred/non-preferred. $1^{\circ}$ week before the commencement of the virtual social training, student pre-test measures were administered, followed by eight, $45^{\circ} \mathrm{min}$ social coaching sessions. Student post-test measures were conducted no more than $1^{\circ}$ week after the conclusion of the virtual social training. All student procedures were conducted within a $4-5^{\circ}$ week time period, depending on student availability and the school calendar. Students completed pre and post-test measures individually, and then, to establish feasibility of delivering the training within the natural context of the school setting, participants were matched with a peer that was performing at a similar competency level for the duration of the virtual social training. Other feasibility factors included accommodating for more students, delivering intervention within limited times during the school day, and meeting administrator requests. Participants who were observed by study staff to have difficulty attending within the virtual environment $(\mathrm{n}=$ 8) were assigned individual training sessions although no difference in the delivery of the training or coaching existed, thereafter. Participants then individually completed the virtual social training post-test. All participants, both paired and individual, completed eight sessions of the virtual social training as well as $1^{\circ} \mathrm{h}$ pre-test and post-test sessions each.

\section{Measures}

The Teacher form of the Social Skills Improvement SystemRating Scale (SSIS-T; Gresham and Elliott, 2008) assessed students' social skills preceding and approximately $5^{\circ}$ weeks following the virtual social training. The SSIS-T is one of the aforementioned 10 assessment tools for teachers and is a normreferenced, standardized scale that provides a broad assessment of students' social skills across seven domains using 46 items and problem behaviors across five domains using 30 items. Subscales related to social skills include data on areas such as communication and assertion, while the problem behaviors domain looks at areas such as internalizing problems, externalizing problems, and hyperactivity. All items are rated on a four-point frequency scale: Never, Seldom, Often, and
Almost Always. As documented in the SSIS Rating Scales Manual (Gresham and Elliott, 2008), there is substantial evidence for the reliability and validity of the score inferences made from the SSIS-T scales and subscales. Test-retest indices for Total Social Skills were 0.82 for the teacher version with median stability indices for the Social Skills and Problem Behavior subscales in the $0.80 \mathrm{~s}$.

The Developmental Neuropsychological Assessment-II Affect Recognition (NEPSY-II AR; Korkman et al., 2007), a subcomponent of this social perception subtest, was used to measure participants' ability to recognize others' emotions. This subcomponent includes three task areas that require participants to select photographs where children appear to be feeling the same way. NEPSY-II AR has high reliability coefficients ( $\mathrm{rs}=0.85-0.87$ ) and moderate test-retest coefficients ( $r s=0.50$ to 0.58 ; Brooks et al., 2010).

The Social Attribution Task (SAT) measured participants' understanding of social accuracy, attribution, and intentionality (Abell et al., 2000). In this experimental measure, adapted from the original videos of Heider and Simmel (1944), participants were asked to narrate the movements of blue and red triangles presented in six separate brief videos. In the current study, pre and post-test administrations were randomized, and two different sets of six videos were used for each participant. For the first three videos, participants were instructed to "Watch each video. At the end of each video, you will describe what you think the triangles were doing." Then, before the start of the last three videos, the participants were prompted to "Pretend the triangles are people, and tell me what they are doing." Narratives were recorded, transcribed, and double-scored by two blind raters. Using methods of (Castelli et al., 2000) each video from the SAT was given a total and intentionality score both based on a sixpoint Likert scale, as well as an accuracy score based on threepoint Likert scale methods (Heider and Simmel, 1944). For the intentionality score, more points were awarded when the participant used mental state vocabulary such as "scared," "surprised," "trick," "bully," etc. to describe the movement of the triangles (e.g., "Parent coaxing a child to go outside" received higher points than "A triangle moving around in a box").

The Social Language Development Test (SLDT; Elementary and Adolescent Editions) Making Inferences subtest was administered to formally assess participants' ability to use contextual clues (i.e., facial expressions, gestures, and posture) to infer a pictured character's perspective. During the Making Inferences subtest of the SLDT, the student takes the perspective of someone in a photograph and tells what the person is thinking as a direct quote. The second question in each item asks the student to identify the relevant visual clues supporting the character's thought. Scoring for SLDT Making Inferences subtest includes assigning a score of one or 0 to each response, based on relevancy and quality. The SLDT has demonstrated good test-retest reliability (SLDT-Elementary $\kappa$ $=0.79$ SLDT-Adolescent $\kappa=0.82$ ), excellent interrater reliability (SLDT-Elementary 84\%, SLDT-Adolescent 85\%), and good content and criterion validity (Bowers et al., 2008; Bowers et al., 2010). 


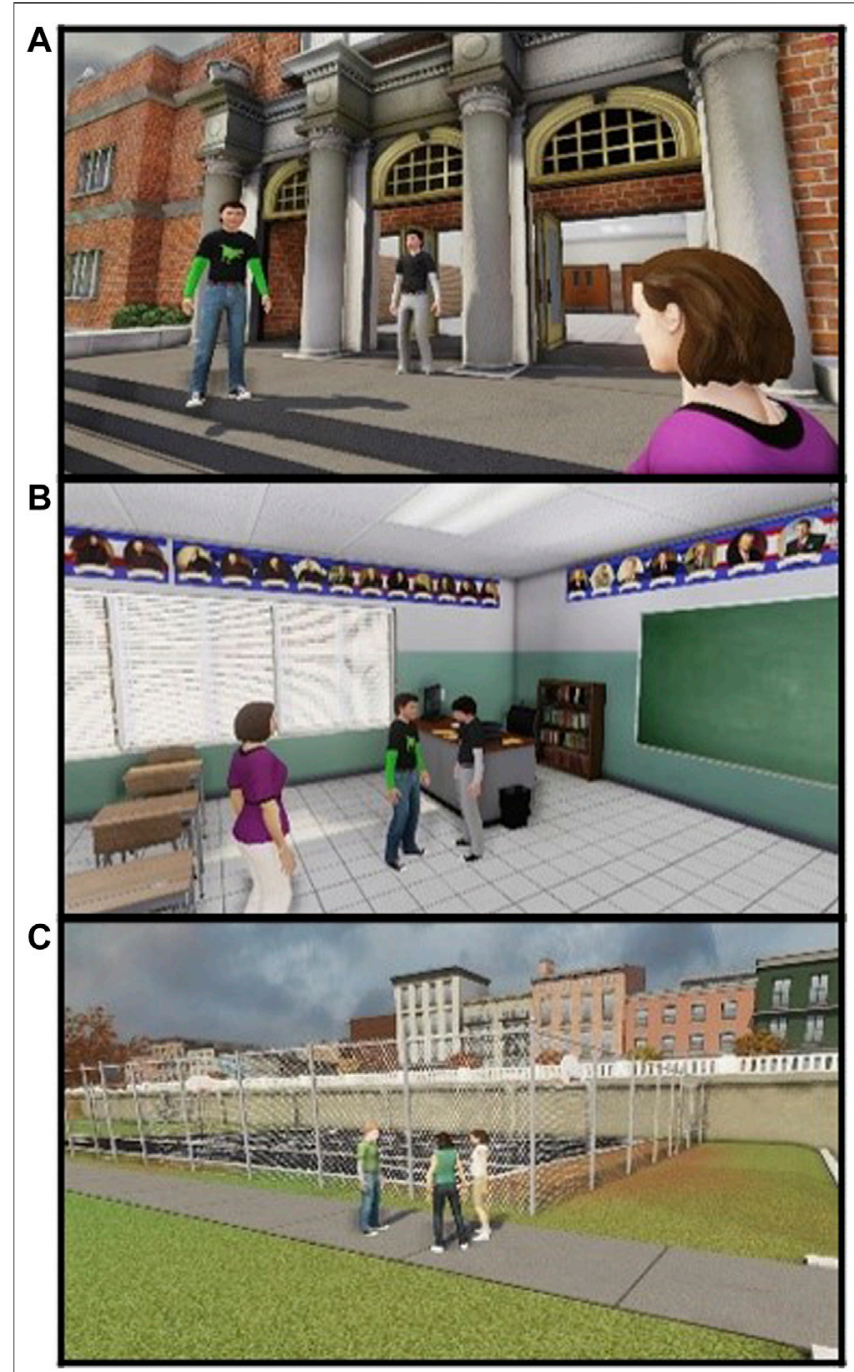

FIGURE 1 | Virtual locations (A) Outside school; Participant, Faux Peer, Coach (B) School classroom; Participant, Faux Peer, Coach (C) Playground and Basketball Courts; Participant, two Faux Peers.

An informal student interview was conducted upon completion of the eight-session virtual social training. Students were asked to report subjective areas of growth and provide insight into their progress. A clinician queried which elements of the virtual social training were most beneficial and applicable to students' daily lives. Lastly, a user experience form was completed by participants to share their impressions of interacting within the virtual social training environment.

\section{Virtual Social Training Environment}

Virtual Gemini $^{\mathrm{TM}} 3.0$ (VG3) was developed at The University of Texas at Dallas' Center for BrainHealth. The Center for BrainHealth's Emerging Technology Lab brought the vision of researchers and clinicians to life as a secure online multiplayer simulation. The VG3 was an immersive 3D platform built on a full source code version of Unreal Engine via the Unreal Development Kit. The virtual world takes the form of a city neighborhood block with access to many environments that are designed to facilitate social role-play. Participants and clinicians were represented in the virtual world by full-body avatars selected to match gender, general height, eye color, hair color, and clothing preferences. Virtual locations (Figure 1) included were a school, a grocery store, an apartment building, a coffee house, a bookstore, and an outdoor city central square area. Exterior features within the city square included the business fronts of a movie theater, restaurant, electronics store, and a pharmacy, all of which provided additional real-world context.

Navigating the virtual world was achieved via use of a USBcompatible console controller. Locomotion and interactions such as run, walk, jump, sit, stand and interact with props were mapped to that of conventional gaming norms. Additionally, participants were provided a gaming headset with microphone for voice communication before, during, and after the experience in the virtual world. Voice over Internet Protocol (VOIP) was handled by Mumble, chosen for its simple user interface and low latency. Clinicians needed the additional functionality of voice manipulation to facilitate the portrayal of many different personas in a single coaching session. For this, the study used MorphVox ${ }^{\mathrm{TM}}$ to manipulate pitch and tone to create simulated voices for various clinician-controlled characters as needed, regardless of age or gender. No participants exhibited difficulty utilizing the technology.

\section{Intervention}

The virtual social training was designed to include a dynamic, eight-session social coaching protocol, with established themes and strategy focus as well as coaching targets, administered within a virtual world (Figure 2). A team of two clinicians was assigned to each student or pair of students to fulfill two distinct clinical roles. Assigned as the "lead" coach, the first of the two clinicians provided onsite user support, in-person instruction of the social strategies, and real-time social coaching within the virtual world (Figure 3). The second role was filled by a confederate-clinician that interacted with participants exclusively as "faux peers" in the virtual world and was implemented from a remote location at the Center for BrainHealth. To ensure quality and consistency, a clinician scenario guide was developed to guide the "faux peer" in assuming the personas of multiple characters with unique personality traits and varying intentions over 40 total simulated social interactions (Figure 4). All sessions were designed to allot sufficient time for each participant or participant pair to receive 5-10 min of virtual social training strategy instruction and four virtual conversations with the "faux peers", with social coaching between each conversation. Parents and teachers were informed that the confederate-clinician would play these multiple characters, while the participants were simply told that the people they were talking to were "real people" and were instructed to "Interact with the other avatars just like you would normally act with people in the real world." Study staff were instructed to not direct the participants on what to say or do during the social interactions. After each conversation, the lead coach utilized a social coaching approach with guided discussion developed from the SIP model. All participants, regardless if paired or individual, were asked to identify if and when they were 


\begin{tabular}{|c|c|c|}
\hline SESSIONS & THEME \& STRATEGY FOCUS & $\begin{array}{c}\text { SOCIAL COACHING } \\
\text { TARGETS }\end{array}$ \\
\hline \multicolumn{3}{|c|}{ Pre Coaching-Establish Dynamic Conversational Social Competency Baseline } \\
\hline \#1 & $\begin{array}{l}\text { Establishing Social Presence; Meeting } \\
\text { New Classmates and School Counselor }\end{array}$ & $\begin{array}{l}\text { Sustain engagement, interest in } \\
\text { others, recognize others' states, } \\
\text { perspectives, motives, opinions }\end{array}$ \\
\hline \#2-3 & $\begin{array}{l}\text { Developing Conversations; Responding } \\
\text { to Others and Expressing Interests }\end{array}$ & $\begin{array}{l}\text { Engage in conversation, share } \\
\text { thoughts, opinions, experience, } \\
\text { ask questions, make social } \\
\text { connections, and relate to others }\end{array}$ \\
\hline \#4 & $\begin{array}{l}\text { Developing Assertion; Understanding } \\
\text { Nuances of Others' Reasoning, Decision } \\
\text { Making and Intentions }\end{array}$ & $\begin{array}{l}\text { Consider multiple points of view } \\
\text { to evaluate a situation for } \\
\text { potential problems. Affirm, } \\
\text { negotiate, challenge, and } \\
\text { compromise to explore many } \\
\text { different perspectives }\end{array}$ \\
\hline \#5 & $\begin{array}{l}\text { Developing Empathy; Customizing } \\
\text { Responses and Sharing Personal } \\
\text { Experiences }\end{array}$ & $\begin{array}{l}\text { Relate insights and provide } \\
\text { relevant examples and support } \\
\text { based on social inferences }\end{array}$ \\
\hline \#6 & $\begin{array}{l}\text { Asserting \& Confronting Peers \& } \\
\text { Adults; Responding to Risky Situations }\end{array}$ & $\begin{array}{l}\text { Determine safety, risk, and } \\
\text { actions to take, consider best } \\
\text { interest for self and others to } \\
\text { make strong, assertive choices }\end{array}$ \\
\hline \#7 & $\begin{array}{l}\text { Maintaining Relationships; } \\
\text { Transforming and Adapting Thoughts, } \\
\text { Emotions, and Actions }\end{array}$ & $\begin{array}{l}\text { Share related questions, ideas, } \\
\text { experiences, and/or feelings that } \\
\text { best fit the context of a given } \\
\text { social situation with preferred } \\
\text { peers }\end{array}$ \\
\hline \#8 & $\begin{array}{l}\text { Asserting with Close Peers; Balancing } \\
\text { and Thriving in Difficult Situations }\end{array}$ & $\begin{array}{l}\text { Recognize misguided or } \\
\text { shortsighted ideas and } \\
\text { intentions, respond with novel } \\
\text { solutions while maintaining } \\
\text { relationships }\end{array}$ \\
\hline
\end{tabular}

FIGURE 2 | Virtual social training session design.

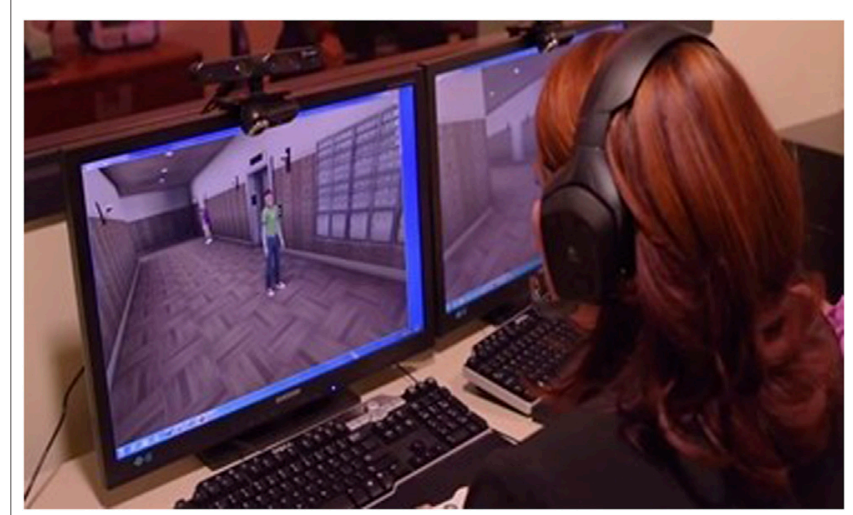

FIGURE 3 | Lead social coach. Virtual apartment, participant avatar. using the social strategies and to explain how the strategies were impacting their ability to recognize social cues and respond to others. For students receiving individual training sessions, due to having difficulty attending within the virtual environment, the lead coach used frequent verbal cues to redirect focus and engagement within the virtual world. Two-thirds of the interactions took place with peers, and one-third took place with adults. Conversations took place within the virtual world at the following virtual locations: apartment complex (15\%), school (44\%), and city square (41\%), with more conversations taking place in academic and social environments to ensure contextual appropriateness for the adolescent years.

\section{Analyses}

To test the hypotheses that teachers are reliable identifiers of middle school students with lagging social skills, standardized 
Session 4 -Theme Introduction: You're coming back to the group today and have a group project with your friends. Meet with your counselor first to understand your activities for the day, then meet with friends to work on a project. After you talk with each person you'll come back here and talk with me.

Social Coaching Target: Consider multiple points of view to evaluate a situation for potential problems. Affirm, negotiate, challenge, and compromise to explore many different perspectives

\begin{tabular}{|c|c|c|}
\hline Location & $\begin{array}{l}\text { Prompt given by } \\
\text { Clinician }\end{array}$ & Clinician Scenario Guide \\
\hline School Office & $\begin{array}{l}\text { Today is Project } \\
\text { Day. Mrs. Sands will } \\
\text { fill you in on the } \\
\text { details. She should } \\
\text { be in the school. }\end{array}$ & $\begin{array}{l}\text { Ms. Laur en Sands (adult female) } \\
\text {-Greet participant warmly. Indicate that you have a fun project that every one will work } \\
\text { on. Wait for response. } \\
\text {-Indicate that the project is a group engineering/science project where the group will } \\
\text { work together to come up with a project to do. It can be any topic but has to be a project } \\
\text { that every one can do. Pause and ask for questions. } \\
\text {-Indicate the participant will work with one person at a time and have } 3 \text { different steps to } \\
\text { do the project: (pause as you explain each step) } 1^{\text {st }} \text { friend - come up with project topic, } \\
2^{\text {nd }} \text { friend - come up with how to do it, } 3^{\text {rd }} \text { friend - complete the project. } \\
\text {-Talk with the participant and offer any help or guidance as needed. Let them know } \\
\text { you'll follow-up tomorrow to see how it goes. }\end{array}$ \\
\hline \multicolumn{3}{|r|}{ Interactive Coaching \& Student Reflection } \\
\hline $\begin{array}{l}\text { School } \\
\text { Classroom }\end{array}$ & $\begin{array}{l}\text { The } 1^{\text {st }} \text { person that } \\
\text { you will be working } \\
\text { on the project with } \\
\text { is Erin. She is in the } \\
\text { classroom already. }\end{array}$ & $\begin{array}{l}\text { Erin (female friend) } \\
\text {-Greet participant and sound bossy - mention you do this every year and it's always } \\
\text { boring. Mention that this year you want to do something you want to do - strongly } \\
\text { suggest something around sports. Wait for response. } \\
\text {-If the participant offers any suggestions, sound annoyed and shoot down all his/her } \\
\text { ideas. Insist you want a project around sports. } \\
\text {-If participant refuses then reluctantly listen to ideas but still refuse saying they are } \\
\text { "dumb" or "boring." } \\
\text {-If participant accepts then sound happy and work together to come up with a good } \\
\text { project for you. (e.g., create a super ball that is aerodynamically shaped to fly faster) }\end{array}$ \\
\hline \multicolumn{3}{|r|}{ Interactive Coaching \& Student Reflection } \\
\hline $\begin{array}{l}\text { School } \\
\text { Play ground }\end{array}$ & $\begin{array}{l}\text { Michael has been } \\
\text { assigned to your } \\
\text { group. He should be } \\
\text { meeting up with you } \\
\text { soon. }\end{array}$ & $\begin{array}{l}\text { Michael (male friend) } \\
\text {-Greet participant in a friendly manner. See if participant tells you the situation. If not } \\
\text { ask what you will be helping on for the project. } \\
\text {-Indicate you are really excited about the sports topic and can think of A LOT of ways to } \\
\text { work on the project. } \\
\text {-Be open minded to suggestions that the participant makes but list a lot of solutions on } \\
\text { your own (without paying too much attention to the participant's ideas). } \\
\text {-If participant tries to offer suggestions, then go along with those to incorporate. } \\
\text {-If participant does not offer suggestions, then encourage the participant to help. } \\
\text {-Indicate you have to leave early and are sad you can't help with the rest of the project. }\end{array}$ \\
\hline \multicolumn{3}{|r|}{ Interactive Coaching \& Student Reflection } \\
\hline $\begin{array}{l}\text { School } \\
\text { Hallway }\end{array}$ & $\begin{array}{l}\text { Tyler is part of the } \\
\text { project too. I think } \\
\text { he will be going into } \\
\text { the classroom. }\end{array}$ & $\begin{array}{l}\text { Tyler (male friend) } \\
\text {-Greet participant and sound bored/disappointed. Wait for response. } \\
\text {-See if participant tells you the situation. If not, then indicate you heard from Michael } \\
\text { what you'll be working on. Sound upset and angry. You don't want to work on this } \\
\text { project. } \\
\text {-Refuse to help, even if participant tries to encourage you. } \\
\text {-Listen the participant but come up with excuses not to help (you can do it on your own, } \\
\text { you don't need me, this is stupid anyway, you don't have everything you need to do the } \\
\text { project, the teacher won't know). Finally insist that your sister should do it since she } \\
\text { was the one that came up with the idea. } \\
\text {-Storm off as you are refusing to help (going to go tell her to do the project by herself). }\end{array}$ \\
\hline \multicolumn{3}{|r|}{ Interactive Coaching \& Student Reflection } \\
\hline
\end{tabular}

FIGURE 4 | Confederate-clinician/faux peer scenario guide- session four.

rating scales measuring social skills and problem behaviors were provided to classroom teachers for each participant. Results were then compared to baseline performance measures in the areas of emotion recognition, social inference, and social attribution to determine any association between teacher observations of social behavior and student performance. It was expected that student classroom-based social skills were 1) positively associated with one or more areas of social competence at baseline, and 2) negatively related to problem behaviors. Additionally, pre-post participant performance data and study completion rate were measured to establish the feasibility and effect of the implementation of an eight-session virtual social training within a naturalized context of public school. Lastly, to test the hypothesis that student participants would transfer skills into the classroom setting $5^{\circ}$ weeks following the training, a post-training rating scale was completed by teachers. Again, expected findings were that implementation of an eight-session virtual social training in a public middle school setting would yield a positive impact on classroom social skills.

Two sets of general linear mixed models were implemented to accommodate the aims of this study, testing the association of student social performance measures with teacher assessments of social behaviors and effects of the virtual social training on each of those measures. The first set modeled each of the teacher assessments as a function of the students' social competency, diagnostic category of each student (non-clinical, attention deficit hyperactivity disorder, other health impairment, autism spectrum disorder, and learning disability), time (pre- and post-training), and all pair-wise and three-way interactions of those factors. The primary test of interest was the association of the student 
TABLE 2|Association between Teacher Report and Baseline Measures of Social Competency. Tests of regression coefficients, SSIS-T sub-scale associations with NEPSYII (left) and SLDT (right).

\begin{tabular}{|c|c|c|c|c|c|c|c|c|}
\hline \multicolumn{5}{|c|}{ Association with NEPSY-Il: Affect recognition } & \multicolumn{4}{|c|}{ Association with SLDT: Making inferences } \\
\hline $\begin{array}{l}\text { SSIS-T } \\
\text { subscales }\end{array}$ & Coefficient & T-value & df & $p$-value & Coefficient & T-value & df & $p$-value \\
\hline Communication & 0.26 & 2.24 & 88.7 & $0.027^{\star}$ & 0.08 & 1.26 & 68.5 & 0.213 \\
\hline Cooperation & 0.29 & 2.40 & 84.5 & $0.018^{*}$ & 0.10 & 1.36 & 73.8 & 0.177 \\
\hline Assertion & 0.09 & 0.70 & 90.8 & 0.484 & -0.02 & -0.29 & 73.5 & 0.771 \\
\hline Responsibility & 0.27 & 2.40 & 88.8 & $0.019^{\star}$ & 0.06 & 0.95 & 69.8 & 0.343 \\
\hline Empathy & 0.04 & 0.28 & 97.7 & 0.778 & 0.14 & 1.87 & 61.5 & 0.066 \\
\hline Engagement & 0.17 & 1.19 & 96.9 & 0.237 & 0.04 & 0.46 & 62.5 & 0.649 \\
\hline Self control & 0.35 & 2.44 & 95.1 & $0.017^{\star}$ & 0.12 & 1.52 & 63.1 & 0.132 \\
\hline Social skills total & 1.57 & 2.14 & 98.9 & $0.035^{\star}$ & 0.30 & 0.81 & 62.1 & 0.422 \\
\hline \multicolumn{9}{|c|}{ SSIS-T problem behavior subscales } \\
\hline Externalizing & -0.35 & -2.16 & 72.9 & $0.034^{\star}$ & -0.31 & -2.63 & 83.5 & $0.010^{*}$ \\
\hline Bullying & -0.02 & -0.26 & 88.5 & 0.793 & -0.06 & -1.40 & 70.3 & 0.165 \\
\hline Hyperactivity & -0.24 & -1.86 & 81.4 & 0.066 & -0.23 & -2.85 & 80.1 & $0.006^{*}$ \\
\hline Internalizing & -0.21 & -1.56 & 87.5 & 0.123 & -0.02 & -0.29 & 69.2 & 0.769 \\
\hline Problem behavior & -0.94 & -2.12 & 87.1 & $0.037^{\star}$ & -0.33 & -1.23 & 77.3 & 0.221 \\
\hline Autism spectrum & -0.29 & -1.26 & 93.6 & 0.212 & -0.15 & -1.34 & 68.7 & 0.184 \\
\hline
\end{tabular}

${ }^{\star} F D R=0.10$

TABLE 3 | Student Social Skill Performance Post Training. SLDT- E and A reported in standard score, other measures reported using raw score; Neuropsychological Assessment (NEPSY-II), Social Attribution Task (SAT), Social Language Development Test Elementary and Adolescent (SLDT- E and A).

\begin{tabular}{|c|c|c|c|c|c|}
\hline Measure & Baseline Mean & Post mean & $\mathbf{T}$ & Df & $p$-value \\
\hline \multicolumn{6}{|l|}{ Measures of social competency } \\
\hline NEPSY-II: Affect recognition & 25.59 & 26.91 & 2.89 & 86.0 & $0.005^{*}$ \\
\hline SAT: Total & 16.40 & 18.12 & 4.56 & 86.0 & $0.000^{*}$ \\
\hline SAT: Intentionality & 11.65 & 13.55 & 4.21 & 86.0 & $0.000^{*}$ \\
\hline SAT: Accuracy & 6.31 & 7.23 & 2.86 & 86.0 & $0.005^{*}$ \\
\hline SLDT-E and A: Making inferences & 82.74 & 91.86 & 6.44 & 71 & $0.000^{*}$ \\
\hline
\end{tabular}

${ }^{*} F D R<0.05$

measures with the teacher assessments, but the other factors and interaction terms were included in the event they influenced the teacher ratings. Average regression coefficients for each dependent variable were converted to t-statistics, which formed the basis for inference. Application of the false discovery rate (FDR) method controlled for multiple testing. The second set modeled each student competency measure and each teacher assessment separately as a function of diagnostic category (listed above), time (pre- and posttraining), and the interaction between these two factors. The primary test of interest was the mean change due to virtual social training, but included diagnostic category in the event that the effect of training depended on one or more of these clinical groups, however, no relevant interactions were found. As above, inference for mean change following training was based on t-statistics, and multiple testing was controlled by the FDR method.

For both sets of models, separate variance components for within-subject measurements (pre- and post-training measures) and for between-subject measures were estimated. This was done not only to allow multiple factors in the linear models, but also to accommodate missingness in some of the time points. This linear based ANOVA model, was reported as t-statistics instead of
F-statistics. Measurements that were not paired in time were not excluded. Model parameters were estimated by maximum likelihood (ML) or restricted ML for variance components; and all models, estimates, and tests were written in the $\mathrm{R}$ statistical computing language ( $\mathrm{R}$ Core Team, 2017). The FDR method was applied to each of the sets of models, and the FDR level was controlled at 0.10 .

\section{RESULT}

\section{Association Between Teacher Report and Baseline Measures of Social Competency}

Table 2 presents data that examines the relationship between the teacher ratings and measures of social competency at baseline. The NEPSY-II AR subtest had a high positive association with the majority of the SSIS-T Social Skills Subscales (i.e., Communication, Cooperation, Responsibility, Self-Control) as well as the Total Social Skills raw score. There was also a high negative association with SSIST Problem Behavior subscale of Externalizing as well as The Total Problem Behavior score. Normed standard scores on the SLDT Making Inferences subtest had a strong negative association with the SSIS-T Externalizing and Hyperactivity subscales. 
TABLE 4 | Classroom Behavior $5^{\circ}$ Weeks Post Training. Reported in raw scores; Social Skills Improvement Rating Scale- Teacher (SSIS-T)

\begin{tabular}{|c|c|c|c|c|c|}
\hline Measure & Baseline mean & $\begin{array}{c}5^{\circ} \text { Week follow-up } \\
\text { mean }\end{array}$ & $\mathbf{T}$ & Df & $p$-value \\
\hline \multicolumn{6}{|c|}{ Teacher rating: SSIS-T subscales } \\
\hline & & & 2.38 & 50.2 & \\
\hline \multirow[t]{2}{*}{ Cooperation } & 11.30 & 11.39 & & & 0.827 \\
\hline & & & 0.22 & 49.2 & \\
\hline Assertion & 8.47 & 9.76 & & & $0.004^{*}$ \\
\hline & & & 0.50 & 51.3 & \\
\hline \multirow[t]{2}{*}{ Empathy } & 8.30 & 8.39 & & & 0.873 \\
\hline & & & 0.16 & 53.6 & \\
\hline \multirow[t]{2}{*}{ Engagement } & 9.44 & 9.94 & & & 0.396 \\
\hline & & & 0.85 & 53.2 & \\
\hline Self-control & 11.36 & 11.74 & & & 0.514 \\
\hline Externalizing & & & 0.27 & 46.9 & \\
\hline \multirow[t]{2}{*}{ Bullying } & 1.69 & 1.87 & & & 0.481 \\
\hline & & & 0.71 & 50.0 & \\
\hline \multirow[t]{2}{*}{ Hyperactivity } & 6.39 & 6.19 & & & 0.648 \\
\hline & & & -0.46 & 48.3 & \\
\hline \multirow[t]{2}{*}{ Internalizing } & 6.67 & 6.57 & & & 0.828 \\
\hline & & & -0.22 & 50.2 & \\
\hline \multirow[t]{2}{*}{ Problem behavior } & 22.83 & 21.27 & & & 0.346 \\
\hline & & & -0.95 & 50.2 & \\
\hline \multirow[t]{2}{*}{ Autism spectrum } & 17.56 & 16.04 & & & 0.087 \\
\hline & & & -1.75 & 52.1 & \\
\hline
\end{tabular}

${ }^{*} F D R<0.05$

\section{Student Social Skill Performance Post Training}

Whole group data on measures of social competency were examined for statistical significance (Table 3). Paired t-tests comparing pre-test and post-test differences for the total sample $(\mathrm{N}=90)$ revealed significant increases on NEPSY-II AR mean raw scores. There was also significant improvement on the SAT total scores as well as intentionality and accuracy subscales $(\mathrm{N}=90)$. Lastly, there was a significant improvement noted on the SLDT Making Inferences subtest $(n=72)$. Standard score conversions are compared due to the elementary and adolescent versions of the test having slightly different scoring procedures and raw score totals.

To further address the feasibility of the training, qualitative data was collected to evaluate each participant's perspective and experience. During the post-training exit interview, participants $(\mathrm{N}=90)$ were queried as to what component of the virtual social training helped the most and why. Sixty-eight percent of participants identified a more confident mindset in regards to their own social communication skills such as relating, maintaining, adapting, and asserting thoughts and ideas. Participants most frequently reported that practicing making connections in the virtual world, either through conversations, shared explorations, world knowledge, and/or developed relationships was the most helpful aspect of the training. The second most frequently reported element was learning a strategy to help evaluate situations and incorporate reactions, feedback, and cues from others to generate novel solutions and implement strong social choices. During this post-training exit interview, no participants reported difficulty using the technology, and the overall technology user experience for this pilot group of sixth through eighth graders was positive. Feedback obtained from students was consistent in that the experience of simulating social situations in a virtual world was fun and interactive, felt "real", and allowed for repeated practice of social strategies in new and engaging ways.

\section{Classroom Behavior Five Weeks Post Training}

Teachers were asked to report on how student participants were engaging socially $5^{\circ}$ weeks after the training (Table 4). Initial data analysis revealed improvement in all social skills subtest areas. Further data analyses revealed statistically significant improvement in the areas of communication and assertion $(n=52)$. At $5^{\circ}$ weeks post training, student participants were reported to communicate more frequently with peers and teachers (i.e., communication) and have greater insight into when to ask for help (i.e., assertion).

\section{DISCUSSION}

The results of this pilot study show that the utilization of virtual social training for adolescents in the middle school environment 
appears to be feasible. Adolescents with lagging social skills are at a disadvantage, as they tend to struggle with accurately recognizing what others think and feel, resulting in poor social communication skills and a negative social mindset. These weaknesses present in a classroom setting as decreased social participation, group work disengagement, and a limited ability to ask for help when needed. Three important contributions of this training study are discussed, followed by the study's limitations which motivate and refine future investigations. The contributions of this research relate to 1) the potential advantage of teacher identification and referral of students struggling socially in middle school; 2) utilizing a virtual environment to simulate real-life interactions with specific social coaching targets and strategies; and 3) the preliminary exploration that virtual social training may have a lasting positive impact on social confidence and behavior in the classroom.

Within the middle school setting, teachers act as key observers of student social behavior. This pilot study supports the feasibility of utilizing teacher identification of social behavior and change, consistent with previous researchers who denote that direct teacher observation of behavior provides essential, real-time information about student functioning and can allow for several potential advantages, such as being used to confirm the presence of a social problem and evaluate student response to intervention (Clemens, et al., 2012; Miller, et al., 2014). Additionally, this work expands on previous studies investigating the validity of teacher ratings of adolescents' social competency levels (Ogden, 2003). With the predominant reasons for referral in this study being shyness/withdrawal and social awkwardness, proactively working with teachers to ensure consistent and reliable identification of students struggling socially may help support quality interactions within the classroom, therefore increasing the likelihood of student confidence, engagement, and participation in classroom discussions. In the face of current societal, economic, environmental, and social challenges, the identification of lagging social skills and promotion of skill development in the educational setting is seen as more critical than ever before. SOCIAL, a socio-cognitive integration of abilities conceptual framework, provides a biopsychosocial understanding of social skill development and proposes that social competence requires cognitive and affective capacities (Beauchamp and Anderson, 2010). The current study builds upon the aforementioned model and adds to the currently limited landscape of social-emotional programming in middle school, as this specific environment demands dynamic and ever-changing social, communicative, and cognitive functions. As such, schools are being urged by political leaders and administrative policy to pay more attention to equipping students with skills such as communication, collaboration, social regulation, and problem-solving, as well as critical thinking (Schonert-Reichl et al., 2017).

Few virtual training programs have demonstrated effectiveness beyond a single study, and a great deal of uncertainty still exists regarding the ideal curriculum and process to develop social skills in a virtual environment (Howard and Gutworth, 2020). We must therefore be cautious in ascribing cause-and-effect relationships between the training and the observed improvements before and after the $5^{\circ}$ week virtual social training. Whereas this is a significant limitation, the results offer promise as supported by the compelling observations across training engagement and teacher-reported improvement. Remotely delivered, individualized social coaching sessions with a trained clinician helped participants understand and integrate this information. Our prior work has shown that social-cognitive strategy training in a virtual environment can generalize beyond the trained domains to neural signatures underpinning social brain health, such as increased brain blood flow, with the brain changes linked to improved complex social cognition, emotional well-being, real-life functions, and social adeptness (Kandalaft et al., 2013; Didehbani et al., 2016; Yang et al., 2017). The present study offers high-quality virtual-based cognitive coaching aimed at teaching tactical social strategies previously shown to improve affect recognition and social engagement. The current paradigm extends the aforementioned approach by exploring the feasibility of training students in a traditional middle school environment with measured social behavior change in the classroom setting. This study replicates laboratory findings in terms of pre-post social performance gains and adds that the virtual social training can be administered in a typical public middle school to improve students' ability to recognize others' emotions, consider perspectives, and interpret intentions, as evidenced by a high completion rate of 80 percent.

Integral to the future of effective and engaging social skill training, technology-based, interactive platforms can be personalized to match the social competency levels and specific social contexts of the adolescent experience while simultaneously teaching and applying new skills. Investigating the value of virtual technology within applied settings within education is an important supplement to classic lab experiments (Makransky et al., 2020). These findings support that a virtual platform for participants to be empowered and self-monitor their application of social strategies may increase student engagement and motivation. Results demonstrated both improvements in quantitative and qualitative measures of social competence and students' reported level of accomplishment and ability.

The present findings have implications that go beyond the promising results of this study. More encouraging is the attainment of positive results while students are in middle school. Investigators found participants' impaired social functioning was identifiable by teachers in a classroom setting, measurable by a standardized assessment battery, and observed by clinicians within an online, virtual environment. Sixth, seventh, and eighth grade may be an opportune time to implement specialized training to improve social competencies. The application of brain science to evidence-based policymaking should address high-level cognitive capacities such as self-awareness, social understanding, and decisionmaking (Choudhury, 2017). Lastly, this work supports recent advances in the study of at-risk youth that indicate a positive, 
strengths-based and preventative approach to working with economically disadvantaged minority youth and encourages a greater focus on identifying resilience-promoting assets within the ecology of one's school, family, and community (Marks et al., 2020).

There were several interesting factors considered from this pilot study that should influence follow-up studies of a similar nature. Analyzing data on the frequency and quality of participants' interactions and strategy use while in the virtual world could help further characterize patterns of social engagement in adolescents, assist in measuring potential response to the virtual social training, and serve as a useful feedback tool for the participants. Although data analyses did not find diagnostic category as an influential factor in the outcomes presented in this study, further exploration of students' social behavior and how related competencies change over time may lead to a more nuanced approach when classifying different types of social learners.

\section{LIMITATIONS}

There are limitations to this pilot study involving study design. In regards to teacher referrals, developing a Likert scale for teachers to rate the social behavior of all students within a class, and then refer at-risk youth may lend to a more dynamic analysis of teacher concerns prior to enrollment in the study. However, the strength of the design was that data was collected in a real classroom environment by the classroom teachers, which made it possible to quickly assess and respond to teacher concerns as well as measure the impact of the virtual training in a realistic setting. Most significantly, this study did not use a control group to isolate the effects of the training. Therefore, causation cannot be established and results must be interpreted with caution. Due to the inclusive nature of this study, it was not possible to develop an experimental design in the given setting because the teachers and administrators did not want to further disadvantage any students in an already at-risk population. To address this, future randomized controlled trials could compare an experimental group to a waitlist control group that engages in conversations with a partner in the virtual world, however, does not receive social coaching or strategies. Nonetheless, virtual social coaching may still offer promise for future interventions. Lastly, this study suffers from issues with missing data, especially concerning the low response rate from teachers (60\% at $5^{\circ}$ weeks post-training). Although teachers reported positive social behavior change $5^{\circ}$ weeks after the training, using a longitudinal approach that extends to multiple populations and age groups would provide a more comprehensive look at generalization effects and social performance across time. A correlational analysis between improved social competency levels and academic achievement could also provide insight into the benefit and lasting effects of an eight-session virtual social training from a holistic social-educational perspective.

Research directions for group-based social interactions within a virtual environment also remain largely unexplored. Evidence suggests that individuals with social challenges most frequently avoid loud, crowded spaces and may benefit from a modifiable, virtual environment to improve social skills (Lau et al., 2020). To further enhance sensory immersion, it may be beneficial from an engagement standpoint to incorporate non-player characters and auditory features such as environmental ambient sound into the virtual world, thereby simulating real-life experiences of small and large group gatherings. Additionally, a platform enhancement suggested by participants was a group gaming component of the virtual experience.

\section{CONCLUSION}

Adolescent social development has critical cognitive elements that govern the processing of information from the social world and drive the attributions that are made. This work provides hope that viable solutions for adolescents struggling socially in the educational setting may eventually be obtained through the provision of evidence-based virtual social training. With advancements in naturally motivating virtual technology, realtime social coaching is a feasible intervention approach that promotes social communication and assertion.

The current study is an innovative and individualized alternative that expands previously stagnated social skill interventions. Furthermore, students demonstrate improved precision in recognizing and understanding social, conversational, and emotional nuances to best formulate and execute a prosocial response, creating a strong, confident foundation for social reasoning and resiliency.

\section{DATA AVAILABILITY STATEMENT}

The original contributions presented in the study are included in the article/Supplementary Material, further inquiries can be directed to the corresponding author.

\section{ETHICS STATEMENT}

The studies involving human participants were reviewed and approved by the University of Texas at Dallas Institutional Review Board and Dallas Independent School District Research Review Board. Written informed consent to participate in this study was provided by the participants' legal guardian/next of kin.

\section{AUTHOR CONTRIBUTIONS}

MJ: Lead author and Senior Speech-Language Pathologist partnering with a team of clinical researchers to translate a lab-based study into real-world application. Utilizing remote technology, Maria's research is dedicated to a keen focus on social cognitive development. AT: Trained as a SpeechLanguage Pathologist, Aimee coaches to the whole student, 
meeting youth at their current level and propelling them forward utilizing evidence-based and scientifically supported solutions. KT: A Speech-Language Pathologist, Kathleen coaches each child through their unique social experiences using personalized strength based training paired with a strategic social-cognitive approach. TA: A senior clinical researcher at the Center for BrainHealth, Tandra oversees programming that promotes social brainhealth across daily living as well as implements assessments and intervention. AT: A director of emerging technology, Aaron oversees the virtual reality social cognition lab. Utilizing virtual technology, Aaron leads a team of graphic artists, programmers, and designs platforms for clinicians to use for virtual social skill training. SC: As a cognitive neuroscientist with more than 40 funded research grants and $200+$ publications, SC scientific discoveries elucidate and deploy novel approaches to advance creative and critical reasoning, strengthen healthy brain development, and expand innovative thinking.

\section{REFERENCES}

Abell, F., Happé, F., and Frith, U. (2000). Do triangles Play Tricks? Attribution of Mental States to Animated Shapes in Normal and Abnormal Development. Cogn. Development 15 (1), 1-16. doi:10.1016/S08852014(00)00014-9

Bayraktar, F., and Amca, H. (2012). Interrelations between Virtual-World and Real-World Activities: Comparison of Genders, Age Groups, and Pathological and Nonpathological Internet Users. Cyberpsychology, Behav. Soc. Networking 15 (5), 263-269. doi:10.1089/cyber.2011.0337

Beauchamp, M. H., and Anderson, V. (2010). SOCIAL: An Integrative Framework for the Development of Social Skills. Psychol. Bull. 136 (1), 39-64. doi:10.1037/ a0017768

Blakemore, S.-J., Burnett, S., and Dahl, R. E. (2010). The Role of Puberty in the Developing Adolescent Brain. Hum. Brain Mapp. 31 (6), 926-933. doi:10.1002/ hbm. 21052

Bowers, L., Huisingh, R., and LoGiudice, C. (2010). Social Language Development Test: Adolescent. IL: East MolineLinguiSystems. doi:10.7551/mitpress/ 9780262014311.001.0001

Bowers, L., Huisingh, R., and LoGiudice, C. (2008). Social Language Development Test: Elementary. IL: East MolineLinguiSystems. doi:10.1037/e527312012-312

Brooks, B. L., Sherman, E. M. S., and Strauss, E. (2009). NEPSY-II: A Developmental Neuropsychological Assessment, Child Neuropsychol. Second edition, 16, 80-101. doi:10.1080/09297040903146966

Cappella, E., Schwartz, K., Hill, J., Kim, H. Y., and Seidman, E. (2019). A National Sample of Eighth-Grade Students: The Impact of Middle Grade Schools on Academic and Psychosocial Competence. The J. Early Adolescence 39 (2), 167-200. doi:10.1177/0272431617735653

Castelli, F., Happé, F., Frith, U., and Frith, C. (2000). Movement and Mind: A Functional Imaging Study of Perception and Interpretation of Complex Intentional Movement Patterns. Neuroimage 12 (3), 314-325. doi:10.1006/ nimg.2000.0612

Choudhury, S. (2017). "Situating the Adolescent Brain: The Developing Brain in its Cultural Context,", in The Adolescent Brain: A Second Window of Opportunity A Compendium. Editors N. Balvin and P. Banati (Florence, Italy: UNICEF Innocenti), 33-39.

Clemens, N. H., Shapiro, E. S., and Seibert, A. L. (2012). "Conducting Systematic Direct Classroom Observations to Define School-Related Problems," in In Assessment for Intervention: A Problem-Solving Approach. Editors R. Brown-Chidsey and K. Arden. 2nd edition (New York: Guilford Press), 157-179.

Crick, N. R., and Dodge, K. A. (1994). A Review and Reformulation of Social Information-Processing Mechanisms in Children's Social Adjustment. Psychol. Bull. 115 (1), 74-101. doi:10.1037/0033-2909.115.1.74

\section{FUNDING}

All funding for this research project was awarded via the Harold Simmons Foundation Smart Community Schools philanthropic grant.

\section{ACKNOWLEDGMENTS}

This research was supported by The Harold Simmons Foundation. We thank our partners from the Dallas Independent School District, the Emerging Technology and Adolescent Reasoning Labs at UT Dallas Center for BrainHealth for their significant contributions, collaborations and involvement with our work. Lastly, generous contributions of time and expertize from researchers, clinicians, and neuroscientists brought their scientific minds together and helped pave the way for this and future projects. For this, we are especially grateful.

Didehbani, N., Allen, T., Kandalaft, M., Krawczyk, D., and Chapman, S. (2016). Virtual Reality Social Cognition Training for Children with High Functioning Autism. Comput. Hum. Behav. 62, 703-711. doi:10.1016/j.chb.2016.04.033

Eklund, K., Kilpatrick, K. D., Kilgus, S. P., and Haider, A. (2018). A Systematic Review of State-Level Social-Emotional Learning Standards: Implications for Practice and Research. Sch. Psychol. Rev. 47 (3), 316-326. doi:10.17105/SPR2017.0116.V47-3

Gamino, J. F., Motes, M. M., Riddle, R., Lyon, G. R., Spence, J. S., and Chapman, S. B. (2014). Enhancing Inferential Abilities in Adolescence: New Hope for Students in Poverty. Front. Hum. Neurosci. 8, 924. doi:10.3389/fnhum.2014. 00924

Gándara, P., and Orfield, G. (2021). Data from: Dallas Diversity and Inclusion Study. SMU Digital Repository. Available at: https://scholar.smu.edu/ texasmexico-research/17/.

Giovanelli, A., Ozer, E. M., and Dahl, R. E. (2020). Leveraging Technology to Improve Health in Adolescence: A Developmental Science Perspective. J. Adolesc. Health 67 (2), S7-S13. doi:10.1016/j.jadohealth.2020.02.020

Gresham, F. M., and Elliott, S. M. (2008). Social Skills Improvement System: Rating Scales. Bloomington, MN: Pearson Assessment.

Haggerty, K., Elgin, J., and Woolley, A. (2011). Social-Emotional Learning Assessment Measures for Middle School Youth. Washington: Raikes Foundation.

Heider, F., and Simmel, M. (1944). An Experimental Study of Apparent Behavior. Am. J. Psychol. 57, 243-259. doi:10.2307/1416950

Howard, M. C., and Gutworth, M. B. (2020). A Meta-Analysis of Virtual Reality Training Programs for Social Skill Development, Comput. Education. A MetaAnalysis of Virtual Reality Training Programs for Social Skill Development, 144, 103707. doi:10.1016/j.compedu.2019.103707

Kaeppler, A. K., and Erath, S. A. (2017). Linking Social Anxiety with Social Competence in Early Adolescence: Physiological and Coping Moderators. J. Abnorm. Child. Psychol. 45, 371-384. doi:10.1007/s10802-016-0173-5

Kamińska, D., Sapiński, T., Wiak, S., Tikk, T., Haamer, R., Avots, E., et al. (2019). Virtual Reality and its Applications in Education: Survey. Information 10, 318. doi:10.3390/info1010031810

Kandalaft, M. R., Didehbani, N., Krawczyk, D. C., Allen, T. T., and Chapman, S. B. (2013). Virtual Reality Social Cognition Training for Young Adults with HighFunctioning Autism. J. Autism Dev. Disord. 43, 34-44. doi:10.1007/s10803-012 1544-6

Korkman, M., Kirk, U., and Kemp, S. (2007). NEPSY. Second Edition. San Antonio, TX: Harcourt Assessment. doi:10.1177/0734282909346716(NEPSY-II)

Lau, B. Y., Leong, R., Uljarevic, M., Lerh, J. W., Rodgers, J., Hollocks, M. J., et al. (2020). Anxiety in Young People with Autism Spectrum Disorder: Common and Autism-Related Anxiety Experiences and Their Associations with Individual Characteristics. Autism 24 (5), 1111-1126. doi:10.1177/1362361319886246

Ma, T.-L., Zarrett, N., Simpkins, S., Vandell, D. L., and Jiang, S. (2020). Brief Report: Patterns of Prosocial Behaviors in Middle Childhood Predicting Peer 
Relations during Early Adolescence. J. Adolescence 78, 1-8. doi:10.101610.1016/ j.adolescence.2019.11.004

Mahoney, J. L., Durlak, J. A., and Weissberg, R. P. (2018). An Update on Social and Emotional Learning Outcome Research. Phi Delta Kappan 100, 18-23. doi:10. $1177 / 0031721718815668$

Makransky, G., Mayer, R., Nøremølle, A., Cordoba, A. L., Wandall, J., and Bonde, M. (2020). Investigating the Feasibility of Using Assessment and Explanatory Feedback in Desktop Virtual Reality Simulations. Education Tech Res. Dev 68, 293-317. doi:10.1007/s11423-019-09690-3

Marks, A. K., Woolverton, G. A., and García Coll, C. (2020). Risk and Resilience in Minority Youth Populations. Annu. Rev. Clin. Psychol. 16, 151-163. doi:10. 1146/annurev-clinpsy-071119-115839

Maskey, M., Lowry, J., Rodgers, J., McConachie, H., and Parr, J. R. (2014). Reducing Specific Phobia/Fear in Young People with Autism Spectrum Disorders (ASDs) through a Virtual Reality Environment Intervention. PLoS One 9 (7), e100374, doi:10.1371/journal.pone.0100374

Miller, F. G., Chafouleas, S. M., Riley-Tillman, T. C., and Fabiano, G. A. (2014). Teacher Perceptions of the Usability of School-Based Behavior Assessments. Behav. Disord. 39 (4), 201-210. doi:10.1177/019874291303900405

Mount, N. J., Chambers, C., Weaver, D., and Priestnall, G. (2009). Learner Immersion Engagement in the 3D Virtual World: Principles Emerging from the DELVE Project. Innovation Teach. Learn. Inf. Computer Sci. 8 (3), 40-55. doi:10.11120/ital.2009.08030040

Nyborg, G., Mjelve, L. H., Edwards, A., and Crozier, W. R. (2020). Teachers' Strategies for Enhancing Shy Children's Engagement in Oral Activities: Necessary, but Insufficient? Int. J. Inclusive Education 64, 1-16. doi:10.1080/ 13603116.2020.1711538

Ogden, T. (2003). The Validity of Teacher Ratings of Adolescents' Social Skills. Scand. J. Educ. Res. 47 (1), 63-76. doi:10.1080/00313830308605

Ogilvy, C. M. (1994). Social Skills Training with Children and Adolescents: a Review of the Evidence on Effectiveness. Educ. Psychol. 14 (1), 73-83. doi:10. 1080/0144341940140105

Payton, J. W., Weissberg, R. P., Durlak, J. A., Dymnicki, A. B., Taylor, R. D., Schellinger, K. B., et al. (2008). The Positive Impact of Social and Emotional Learning for Kindergarten to Eighth-Grade Students: Findings from Three Scientific Reviews. ChicagoSocial, and Emotional Learning: Collaborative for Academic.

R Core Team (2017). The R Project for Statistical Computing. Available at: https:// www.r-project.org/.(Accessed February 11, 2021).

Rapee, R. M., Oar, E. L., Johnco, C. J., Forbes, M. K., Fardouly, J., Magson, N. R., et al. (2019). Adolescent Development and Risk for the Onset of SocialEmotional Disorders: A Review and Conceptual Model. Behav. Res. Ther. 123, 103501. doi:10.1016/j.brat.2019.103501

Schonert-Reichl, K. A., Kitil, M. J., and Hanson-Peterson, J. (2017). To Reach the Students, Teach the Teachers: A National Scan of Teacher Preparation and Social and Emotional Learning. A Report Prepared for the Collaborative for Academic, Social, and Emotional Learning (CASEL). Vancouver, B.C.: University of British Columbia.

Solberg, S., Edwards, A., and Nyborg, G. (2020). Leading for School Inclusion and Prevention? How School Leadership Teams Support Shy Students and Their Teachers. Scand. J. Educ. Res. 64, 1-14. doi:10.1080/00313831.2020.1788156
Taylor, R. D., Oberle, E., Durlak, J. A., and Weissberg, R. P. (2017). Promoting Positive Youth Development through School-Based Social and Emotional Learning Interventions: A Meta-Analysis of Follow-Up Effects. Child. Dev. 88 (4), 1156-1171. doi:10.1111/cdev.12864

Wainer, A. L., and Ingersoll, B. R. (2011). The Use of Innovative Computer Technology for Teaching Social Communication to Individuals with Autism Spectrum Disorders. Res. Autism Spectr. Disord. 5 (1), 96-107. doi:10.1016/j. rasd.2010.08.002

Wang, M.-T., and Eccles, J. S. (2012). Adolescent Behavioral, Emotional, and Cognitive Engagement Trajectories in School and Their Differential Relations to Educational Success. J. Res. Adolesc. 22 (1), 31-39. doi:10.1111/j.1532-7795. 2011.00753.x

West, M. R., Pier, L., Fricke, H., Hough, H., Loeb, S., Meyer, R. H., et al. (2020). Trends in Student Social-Emotional Learning: Evidence from the First LargeScale Panel Student Survey. Educ. Eval. Pol. Anal. 42 (2), 279-303. doi:10.3102/ 0162373720912236

Wilson, D. K., Sweeney, A. M., Kitzman-Ulrich, H., Gause, H., and St. George, S. M. (2017). Promoting Social Nurturance and Positive Social Environments to Reduce Obesity in High-Risk Youth. Clin. Child. Fam. Psychol. Rev. 20 (1), 64-77. doi:10.1007/s10567-017-0230-9

Wohn, D. Y., and Wash, R. (2013). A Virtual "Room" with a Cue: Detecting Personality through Spatial Customization in a City Simulation Game. Comput. Hum. Behav. 29 (1), 155-159. doi:10.1016/j.chb.2012.07.029

Yang, C., Bear, G. G., and May, H. (2018). Multilevel Associations between Schoolwide Social-Emotional Learning Approach and Student Engagement across Elementary, Middle, and High Schools. Sch. Psychol. Rev. 47 (1), 45-61. doi:10. 17105/SPR-2017-0003.V47-1

Yang, Y. J. D., Allen, T., Abdullahi, S. M., Pelphrey, K. A., Volkmar, F. R., and Chapman, S. B. (2017). Brain Responses to Biological Motion Predict Treatment Outcome in Young Adults with Autism Receiving Virtual Reality Social Cognition Training: Preliminary Findings. Behav. Res. Ther. 93, 55-66. doi:10.1016/j.brat.2017.03.014

Yeager, D. S. (2017). Social and Emotional Learning Programs for Adolescents. Future Child. 27 (1), 73-94. doi:10.17105/SPR-2017-0003.V47-110.1353/foc. 2017.0004

Zhao, W., Liu, X., Qiu, T., and Luo, X. (2020). Virtual Avatar-Based Life Coaching for Children with Autism Spectrum Disorder. Computer 53, 26-34. doi:10. 1109/MC.2019.2915979

Conflict of Interest: The authors declare that the research was conducted in the absence of any commercial or financial relationships that could be construed as a potential conflict of interest.

Copyright (c) 2021 Johnson, Troy, Tate, Allen, Tate and Chapman. This is an openaccess article distributed under the terms of the Creative Commons Attribution License (CC BY). The use, distribution or reproduction in other forums is permitted, provided the original author(s) and the copyright owner(s) are credited and that the original publication in this journal is cited, in accordance with accepted academic practice. No use, distribution or reproduction is permitted which does not comply with these terms. 